Revista Temas Socio Jurídicos

Vol. 38 No 76 Enero - Junio de 2019

ISSN: 0120-8578

ISSN electrónico: 2590-8901

\title{
GESTACIÓN POR SUSTITUCIÓN INTERNACIONAL: REFLEXIONES SOBRE UNA RESTRICCIÓN LEGISLATIVA CONSTITUCIONALMENTE VÁLIDA CON RELACIÓN A LA FORMA DEL REGISTRO DE NACIMIENTO Y EL MARGEN DE APRECIACIÓN ESTATAL*
}

\author{
Juan Antonio Flores Hernández** \\ Gabriela Aguado Romero***
}

Recibido: Marzo 16 de 2019

Aprobado: Mayo 2 de 2019

Citar este trabajo como: Flores Hernández, J., \& Aguado Romero, G. (2019). Gestación por sustitución internacional: reflexiones sobre una restricción legislativa constitucionalmente válida con relación a la forma del registro de nacimiento y el margen de apreciación estatal. Temas Socio-Jurídicos, 38(76), pp. 99-129. https://doi.org/ 10.29375/01208578.3581

\footnotetext{
* El presente artículo se enmarca en el Proyecto de Investigación "La gestación por sustitución en el discurso de los sistemas interamericano y europeo de derechos humanos". En conjunto es el resultado parcial de una estancia de investigación bajo la orientación de la Dra. Antonia Durán Ayago, profesora en el Departamento de Derecho Internacional Privado de la Universidad de Salamanca, España, la supervisión como tutora de la Doctora Gabriela Aguado Romero, como cotutora la Doctora Gisela María Pérez Fuentesy, como lectores: el Doctor Gerardo Ribeiro Toral y Lutz Alexander Keferstein Caballero, profesores investigadores en la Universidad Autónoma de Querétaro; con el apoyo del Capítulo Guanajuato de la Academia Nacional de Bioética, A.C., el Proyecto Inocencia con residencia en la ciudad de Guanajuato, México, perteneciente a la red Innocence Proyect con sede en California Wester School of Law, U.S.A. y, la Fundación para la Defensa y Promoción de los Derechos Humanos sita en San José, Costa Rica.

** Candidato a Doctor, Universidad de Querétaro, México, Santiago de Querétaro. Orcid: 0000-0003-2306-3672. Correo electrónico: lic.flores8@gmail.com
}

*** Doctora en Derecho, Profesora Universidad de Querétaro, México, Santiago de Querétaro. Orcid: 0000-0003-3733-6459. Correo electrónico: gabriela.aguado@uaq.mx 


\title{
RESUMEN:
}

En abril de 2017 un tribunal federal, como órgano del sistema de control concentrado de constitucionalidad, emitió en Tabasco una sentencia sobre la determinación de filiación de una menor, derivada de un contrato de gestación por sustitución con padre extranjero en modelo familiar monoparental. El discurso judicial ordenó al Registro Civil la inscripción inmediata del nacimiento de la niña sin necesidad de agotar el procedimiento judicial de adopción e inaplicó la legislación vigente. Sin embargo, se encuentran ocultos argumentos plausibles sobre la restricción legislativa soslayada en torno a la finalidad constitucionalmente válida; la idoneidad para proteger el orden público y el interés de la menor; la necesidad de procurar equilibrio entre el interés de la comunidad en lograr la elección efectuada democráticamente, los peligros derivados de la gestación por sustitución (interés público), el interés del comitente y del menor (intereses privados); la construcción de diversos conceptos de filiación: biológica, genética o de intención; y la intervención judicial y su funcionalidad en la interpretación de la noción de inmediatez en el registro de nacimiento.

Palabras clave: Gestación por sustitución; filiación; Constitución; registro de nacimiento.

\section{INTERNATIONAL GESTATIONAL SURROGACY: REFLECTIONS BETWEEN A CONSTITUTIONALLY VALID LEGISLATIVE RESTRICTION REGARDING HOW THE BIRTH IS REGISTERED AND THE MARGIN OF STATE APPRECIATION}

\begin{abstract}
:
In April 2017, a federal court, as a body of the specialized control system of constitutionality, handed down a sentence in Tabasco on the determination of parentage of a minor, derived from a gestational surrogacy agreement with a foreign father in a single-parent family model. The judicial discourse ordered the Civil Registry to immediately record the girl's birth without the need to exhaust the legal procedure of adoption, and unenforced the current legislation. However, there are reasonable hidden arguments about the eluded legislative restriction regarding the constitutionally valid purpose; the suitability to protect the public order and the minor's interest; the need of finding balance between the community's interest of achieving the democratically conducted election, the dangers derived from gestational surrogacy (public interest), the interest of the principal party and the minor (private interests); the construction of di-
\end{abstract}


verse parentage concepts: biological, genetic or intended; and the legal intervention and its functionality in the interpretation of the notion of immediacy in the birth registration.

Keywords: Gestational surrogacy; parentage; constitution; birth registration.

\section{GESTAÇÃO POR SUBSTITUIÇÃO INTERNACIONAL: REFLEXÕES ENTRE UMA RESTRIÇÃO LEGISLATIVA CONSTITUCIONALMENTE VÁLIDA COM RELAÇÃO À FORMA DO REGISTRO DE NASCIMENTO E A MARGEM DE APRECIAÇÃO DO ESTADO}

\section{RESUMO:}

Em abril de 2017, em Tabasco, um tribunal federal, como órgão do sistema de controle concentrado de constitucionalidade, emitiu uma sentença sobre a determinação da filiação de um menor, derivada de um contrato de gestação por substituição com um pai estrangeiro em um modelo de família monoparental. O discurso judicial ordenou ao Registro Civil o registro imediato do nascimento da criança sem ter que esgotar o processo de adopção e sem levar em conta a legislação vigente. No entanto, há argumentos plausíveis ocultos sobre a restrição legislativa que foi negligenciada em relação ao propósito constitucionalmente válido; a idoneidade para proteger a ordem pública e o interesse da criança; a necessidade de procurar um equilíbrio entre o interesse da comunidade em alcançar a escolha democraticamente eleita, os perigos decorrentes da gestação por substituição (interesse público), o interesse dos envolvidos e do menor (interesses privados); a construção de diferentes conceitos de filiação: biológica, genética ou socioafetiva; e a intervenção judicial e sua funcionalidade na interpretação da noção de imediatismo no registro de nascimento.

Palavras-chave: Gestação por substituição; filiação; constituição; registro de nascimento

\section{INTRODUCCIÓN}

El margen de apreciación que puede tener cada entidad federativa, sobre la ponderación del orden público y el interés social, es una herramienta hermenéutica para justipreciar la legitimación de una intervención legislativa que restrinja un derecho fundamental con la finalidad de perseguir un objetivo constitucionalmente válido. Sobre el tópico de la gestación por sustitución, una vez que han nacido los niños, los problemas que se suscitan con su identidad son el registro de su filiación correspondiente en el ámbito interno, y en el externo, el reconocimiento de esa filiación 
ya establecida al desplazarse al Estado donde se busca que residan permanentemente, como en España con la resolución del Tribunal Supremo del 2 de febrero de 2015 (Durán, 2012, pp. 268-269) o en Francia con los asuntos Mennesson y Labassee.

El propósito de este artículo es comentar la Sentencia de 28 de abril de 2017 emitida por un juzgado de distrito en Tabasco, para analizar el problema de asentamiento del registro de filiación derivada de un acuerdo de gestación por sustitución internacional en relación con una menor nacida y su padre biológico. En ese discurso, cabe destacar que el derecho de familia en México ha logrado cierta autonomía dentro del derecho civil como resultado de un método de política jurídica; lo anterior ocurre por la necesidad de la protección de las personas más débiles y por tanto la protección de la teoría de los derechos humanos a través de la constitucionalización de algunas instituciones tradicionales del derecho civil (Pérez, 2017, p. 146).

Se evidencia que se trata de una política pública del estado de Tabasco para determinar la filiación derivada de la gestación por contrato, la cual impone específicamente el procedimiento judicial de la adopción plena para el asentamiento del recién nacido. Existen argumentos plausibles para sostener: I. La finalidad constitucionalmente válida de la restricción legislativa; II. La idoneidad para proteger tanto el orden público como la vida privada del infante; III. La necesidad equilibrada entre los intereses públicos, privados y peligros derivados de la gestación por sustitución; IV. El ascenso sobre la necesidad de la intervención estatal en el acto reproductivo de la gestación por sustitución para la determinación paterno-filial, vía administrativa, judicial o ambas; V. La falta de consenso para determinar la necesidad de que dicha intervención sea anterior o posterior al parto, en tanto que cada alternativa para determinar la filiación deriva de un sistema de presunciones basado en una construcción ideológica diversa: biológica, genética o de intención; y VI. La intervención judicial posterior al parto por vía de adopción es una alternativa razonablemente breve para reconocer un estatus definido de identidad cierta y que provee de suficientes medios para evitar perjuicios a los menores.

Si bien el derecho como significado es abierto, por no existir una visión única del bien y de lo justo, la función resolutoria acompañada de la fuerza legitimadora del Estado es una herramienta de control social en la necesidad de suprimir el derecho frente a visiones incompatibles entre sí para elegir una de ellas, lo que determina en forma permeable lo que el derecho no es y expulsa la narrativa que no supera un parámetro aceptable (Cover, 1983, p. 40). Los tribunales ordenan que se actúe de determinada manera, o impiden que se actúe de otra. Frente a visiones distintas que promueven resultados diversos el resolutor elige una de ellas. Sin embargo, esta función puede postularse solo en un sentido limitado: la decisión judicial únicamente es final en el sentido de poner fin a un caso 
concreto y resolver un reclamo específico en un lugar y tiempo determinados. La sentencia del tribunal, por sí sola, de ninguna manera pone fin a la controversia social que sirve de trasfondo a ese caso. En los casos difíciles, como el que atañe al presente estudio, la controversia permanece viva en el mundo del derecho pues conviven legítimamente diversas interpretaciones válidas (Álvarez, 2012, p. 83).

En el caso concreto, el señor Aaron Ray Cyr, norteamericano, por su propio derecho y en representación de su hija, la menor Rachel Mary Cyr recién nacida mediante gestación por sustitución con la aportación de su material genético, promovió juicio de amparo en contra de diversos actos de autoridad, solicitando la protección de la justicia federal, en lo que aquí interesa, contra: a) la inconstitucionalidad de los artículos que reformaban la legislación civil del estado de Tabasco en lo relativo a la gestación por sustitución, y b) el acuerdo SG/DGRCT/153/2016 emitido por la Dirección del Registro Civil del estado de Tabasco, el cual declaró improcedente la solicitud de registro de una menor por su padre de intención.

La Dirección General del Registro Civil del estado de Tabasco y su Coordinación Jurídica rindieron informes justificados en el sentido de no declarar improcedente el registro de la infante, solo se concentraron en manifestar las razones por las que resultaban incompetentes para asentar a la menor nacida mediante el procedimiento de "gestación materna sustituta", puesto que atendiendo a que la transferencia embrionaria tuvo lugar el 7 de abril de 2016, durante la vigencia de los artículos 380 bis, 380 bis 1,380 bis 2,380 bis 3,380 bis 4,380 bis 5,380 bis 6 y 380 bis 7 del Código Civil del estado de Tabasco ${ }^{1}$, quien tenía legalmente esa potestad era el juez competente a través de un procedimiento no contencioso de adopción plena.

1 En lo sustancial, los artículos en contexto disponen el marco regulatorio de lo que el Código Civil de Tabasco denomina "contrato de gestación", entre otros: I.- La "gestación por contrato" admite dos modalidades: la subrogada, implica que la gestante sea inseminada aportando sus propios óvulos y que entregue el recién nacido a la madre contratante mediante adopción plena (artículo 382 Bis 2. Formas de Gestación por Contrato, fracción I), y la sustituta, implica que la gestante sea contratada exclusivamente para portar en su vientre un embrión obtenido por la fecundación de gametos de la pareja o persona contratante; ser ciudadanos mexicanos y el procedimiento judicial en el que se centra el presente estudio, $I V$.- El asentamiento del recién nacido deberá realizarse mediante la figura de la adopción plena (artículo 380 Bis 6 . Asentamiento del recién nacido, último párrafo). Por su parte, la adopción plena se regula en los artículos 398, 399, 400, 401, 402 y 403 del Código Civil para el estado de Tabasco. En lo sustancial, se requiere que el menor, entre otros supuestos, sea producto de un embarazo logrado como consecuencia del empleo de inseminación artificial o fertilización in vitro con la participación de una madre sustituta que haya convenido con los presuntos padres darlo en adopción; que los adoptantes tengan medios bastantes para proveer a la formación y educación integral del adoptado; la adopción debe fundarse sobre justos motivos y presentar siempre ventajas para el adoptado, para que la adopción plena tenga lugar deberán consentir en ella, en sus respectivos casos, la persona o personas quienes por la ley ejercen la patria potestad, en este caso la madre subrogada-. 
En el caso que nos ocupa, mediante el trámite por separado del juicio principal y a través de un procedimiento incidental, el juez de distrito concedió la suspensión del acto reclamado consistente en la negativa de expedir el acta de nacimiento de la menor Rachel Mary Cyr y ordenó en consecuencia expedir una en forma cautelar, lo que no fue concretamente solicitado por los demandantes por lo que la orientación instrumental de esa medida se entiende en forma tácita como suplencia de la deficiencia en la pretensión de los solicitantes que el juzgador integró con base en una "interpretación conforme" (Miranda, 2014, pp. 69-80). No obstante, ante ese panorama el Registro Civil solicitó una aclaración manifestando incertidumbre e imposibilidad jurídica para cumplir al no existir en la legislación civil de Tabasco la figura jurídica de acta de nacimiento provisional.

El juez de distrito, en aras de salvaguardar el principio de interés superior del menor, precisó que se había concedido la suspensión:

[...] para que el Titular de la Dirección General del Registro Civil del estado de Tabasco, registre y/o inscriba a la citada menor de edad, debiendo expedirle de manera gratuita, su primer copia certificada del acta de registro de nacimiento. Asimismo... deberá hacer una anotación marginal o hacer constar dentro del acta que ésta es de carácter provisional, imponiendo la obligación a que las autoridades, instituciones o dependencias ante las que se presente ese documento, estarán forzadas a informar el trámite y motivo por el que se les exhibió, hasta en tanto se resuelve el fondo de este asunto; lo anterior, con la finalidad de salvaguardar derechos de un tercero y además que, de no hacerlo así, se dejaría en estado de indefensión a la infante, pues como se ha dicho el derecho a la identidad es un requisito sine qua non para poder acceder a otros diversos, como son la salud, educación, entre otros [...]. (Pérez Chan, 2017)

Por otra parte, el juez de distrito abundó en que en ninguna parte se expresó que el acta debía ser provisional, sino que, por el contrario, se tenía que registrar o inscribir inmediatamente a la menor. Esto se deriva del derecho humano de identidad y la obligatoriedad de ser registrado de manera inmediata a su nacimiento. Aunado a ello, se ordenaba hacer una anotación marginal, lo cual no implica que el acta sea provisional, ni mucho menos pugna con la legislación civil aplicable; tan es así, que el Reglamento del Registro Civil del estado de Tabasco faculta realizar distintos tipos de anotaciones al margen de las actas, como precisamente se ordenó hacer en tanto que el registro o inscripción de la menor deriva de una medida suspensiva que tiene vigencia hasta que cause ejecutoria el juicio de amparo y quede sub judice su validez posterior y que se resuelva mediante sentencia definitiva.

En esas condiciones, al estimar el juez que no se había dado cumplimiento a lo ordenado requirió para que en: 
[...] forma inmediata... dentro de las veinticuatro horas siguientes... sin que haya lugar a prórroga alguna, sirva dar cumplimiento a la medida cautelar; apercibida que, en caso de incumplimiento, se hará acreedora a una multa... Lo anterior, en el entendido que el desacato... podría dar origen... a que este órgano jurisdiccional ordene que se dé vista al Ministerio Público por la probable comisión... del delito de desobediencia [...]. (Pérez Chan, 2017)

En la sentencia definitiva se ordenó al Registro Civil ejecutar los trámites administrativos que se requerían para que se expidiera copia certificada del acta de nacimiento.

Lo singular es que el juzgador hace referencia tácita a un principio de igualdad del menor independientemente de las circunstancias del nacimiento y a una atenuación o "efecto mitigado del orden público" al declarar que en el ordenamiento civil no se encuentra inmerso dispositivo alguno que disponga la prohibición de realizar el asentamiento de un menor a quien demuestre ser su padre biológico.

Con reserva ha de cuestionarse si la resolución judicial fue necesariamente omisa ante la ausencia de la actividad contenciosa de las autoridades llamadas a juicio, o debidamente contenida con relación a un exceso de actividad judicial (Osuna, 2015; Gutiérrez, 2016) y respetuosa de las relaciones familiares de facto e intimidad, para que no sean conocidos por terceros ciertos aspectos de su vida privada; ello al omitir las presunciones del parto y no orientar el interés superior del niño para establecer la integración total de la verdad biológica, puesto que no fue controvertido el resultado de la prueba de exclusión de paternidad realizada por un laboratorio privado, ni se instó para descartar que efectivamente la gestante no hubiera aportado su carga genética.

La idea disidente del presente artículo se centra en dos orientaciones: la primera, la intervención legislativa en el caso de Tabasco no es una medida suprainclusiva, es decir, no es una prohibición absoluta, ni deja desprotegido el derecho a la identidad del menor al permitir el establecimiento de la relación paterno filial mediante un procedimiento de adopción, además de no impedir la unidad familiar en la que pueda estar integrada la menor; la segunda, una interpretación válida y divergente a la literal sobre el enunciado constitucional "[...] Toda persona tiene derecho [...] a ser registrado de manera inmediata a su nacimiento [...]”, para determinar el alcance del término "inmediatez" en un sentido de brevedad razonable.

\section{METODOLOGÍA}

Mediante el Análisis Crítico del Discurso se busca descifrar semánticamente el núcleo duro y discurso político de la identidad y el orden público de la gestación por sustitución como los derechos en colisión, colocando en el centro de la discusión aquellos elementos que permanecen expresos u ocultos en el discurso jurídico, para realizar un test de ponderación. 


\section{CONSIDERACIONES SOBRE LA CONSTITUCIONALIDAD DE LA RESTRICCIÓN LEGISLATIVA}

Partiendo de la idea de que los derechos fundamentales tienen la función de delimitar el núcleo duro de determinado derecho humano (Nino, 1989, p. 223), una especie de área residual (Díez-Picazo, 2005, p. 70) que excluye la actuación estatal del goce de ese derecho reconocido como indispensable, forma un "coto vedado" (Garzón, 1989, p. 209), esto es, un límite negativo al poder público que prohíbe intervenir u obstaculizar las acciones permitidas por el derecho fundamental (Alexy, 2007, pp. 197-201).

Por otra parte, ningún derecho fundamental es absoluto, irrestricto e ilimitado (SCJN, AR 173/2008, p. 34-35). Estos colisionan con límites externos, y otras prerrogativas de terceros y el orden público (objetivos sociales colectivos positivizados) consecuentemente pueden ser intervenidos legislativamente con la finalidad de perseguir un objetivo constitucionalmente válido (Prieto, 2003, p. 222). El legislador está facultado para regular los derechos fundamentales, determinar su contenido y delimitar sus alcances, siempre bajo condiciones dignas y justas cuando se afecten derechos de terceros o de la sociedad en general y no para establecer límites que en su aplicación equivalgan en la realidad a una cancelación de su contenido esencial (SCJN, AR 173/2008, p. 37).

Expuesto así, en la construcción del presupuesto de inicio para el análisis de ponderación es menester fijar que la intervención legislativa que nos ocupa limita el derecho fundamental que domina nuestra atención (Bernal, 2007, p.45), es decir, la política pública del estado de Tabasco sobre filiación derivada de la "gestación por contrato" es una intervención en la vida privada del recién nacido e incide en el contenido prima facie (Barak, 2012, p. 19) del derecho fundamental a la identidad. En atención a que aquella tiene el alcance para imponer específicamente el procedimiento judicial de la adopción plena para el asentamiento del recién nacido, lo que constituye un obstáculo jurídico para el reconocimiento de la paternidad biológica en forma administrativa ante el Registro Civil.

\section{Finalidad constitucional}

La finalidad de la restricción es constitucionalmente válida. El legislador en la exposición de motivos justifica que la finalidad de la intervención es la protección del interés del menor y del orden público estatal. Pretensiones para materializar con la instrumentación de cambios en la forma de probar la filiación (que busca certeza en las formas de acreditarla) y la intervención judicial a fin de tutelar el derecho de familia e impedir la eventual mercantilización de los recién nacidos (Periódico Oficial del Gobierno Constitucional del Estado Libre y Soberano de Tabasco, 2016), son objetivos que legítimamente puede perseguir el estado nación. 
Se enfatiza en la preocupación subyacente del legislador, la eventual mercantilización del menor como motivación de la intervención legislativa a fin de evitar la afectación de los derechos de terceros (recién nacidos) y de la sociedad en general. Finalidades que buscan la realización de un objetivo expresamente previsto en la Norma Fundamental: proteger el derecho a la integridad de los niños, establecido en el párrafo noveno del artículo $4^{\circ}$ Constitucional:

[...] En todas las decisiones y actuaciones del Estado se velará y cumplirá con el principio del interés superior de la niñez, garantizando de manera plena sus derechos. Los niños y las niñas tienen derecho a la satisfacción de sus necesidades de alimentación, salud, educación y sano esparcimiento para su desarrollo integral. Este principio deberá guiar el diseño, ejecución, seguimiento y evaluación de las políticas públicas dirigidas a la niñez [...]. (Pérez Chan, 2017)

La protección consistente en no establecer un vínculo paterno filial entre el menor y el comitente, derivada de la eventualidad de mercantilización y el interés del niño evidenciados en un procedimiento judicial, es una excepción reconocida en el artículo 16 del Protocolo Adicional a la Convención Americana sobre Derechos Humanos en Materia de Derechos Económicos, Sociales y Culturales "Protocolo de San Salvador":

[...] Todo niño sea cual fuere su filiación tiene derecho a las medidas de protección que su condición de menor requiere por parte de su familia, de la sociedad y del Estado. Todo niño tiene el derecho a crecer al amparo y bajo la responsabilidad de sus padres; salvo circunstancias excepcionales, reconocidas judicialmente, el niño de corta edad no debe ser separado de su madre. Todo niño tiene derecho a la educación gratuita y obligatoria, al menos en su fase elemental, y a continuar su formación en niveles más elevados del sistema educativo [...]”. (OEA, 1988)

\section{Idoneidad}

Es idónea la intervención para proteger tanto el orden público como la vida privada del infante. Existe evidencia que relaciona la gestación por sustitución y una situación de peligro que afecta el orden público y los derechos del infante. Aun cuando se pueda sostener que se trata de afectaciones de escasa entidad, ello no es obstáculo para afirmar que, la medida legislativa que instrumenta cambios en la forma de probar la filiación y la intervención judicial a fin de tutelar el derecho de familia e impedir la eventual mercantilización, es idónea para proteger tanto el orden público como el interés del menor.

Para identificar la idoneidad de la restricción y alcanzar el propósito del legislador, se debe evaluar a partir de conocimientos científicos o convicciones sociales generalmente aceptadas y verificar la existencia de una relación empírica entre la intervención al derecho y el fin que persigue 
esta afectación; es suficiente que la medida contribuya en algún modo y en algún grado a lograr el objetivo del legislador (Bernal, 2007, P. 733), es decir, si la correlación entre medio y fin es positiva con independencia de su nivel de eficacia.

Del examen de la literatura que ha analizado la gestación por sustitución puede identificarse, con relación al recién nacido, un efecto negativo: la cosificación del menor al convertirlo en objeto de propiedad o comercio (Pérez Fuentes, 2017, p. 130).

En este sentido se han alzado diversas opiniones: el Comité Consultatif National d'Ethique pour les sciences de la vie et de la santé de Francia ha manifestado que la gestación por sustitución puede servir a intereses comerciales y puede causar secuelas emocionales en los hijos (opinión número 3, 1984; opinión número 90, 2005; opinión número 110, 2010); la Comisión Especial de Estudio de la Fecundación In Vitro y la Inseminación Artificial Humanas en España, en su informe de 1986 concluye que de la gestación por sustitución derivan interrogantes de carácter legal de difícil interpretación como la existencia de conflictos derivados de una comercialización descubierta (Palacios, 1986. p. 166); la Oficina Permanente de la Conferencia de la Haya de Derecho Internacional Privado estudia actualmente las cuestiones de derecho internacional privado que se encuentran en relación con el origen legal de los niños, así como la relación con los acuerdos internacionales de subrogación. El proyecto denominado "Filiación y Maternidad Subrogada" señala en su presentación que es bien sabido que la subrogación es un negocio global $(\mathrm{HCCH}$, 2010); el informe del Comité Ad Hoc de Expertos sobre el Progreso de las Ciencias Biomédicas en el Consejo de Europa, el cual ha sido considerado por la Corte Europea de Derechos Humanos en el caso Mennesson y Labassee, publicó en 1989 una serie de principios; el decimoquinto relativo a las madres sustitutas, señala:

[...] cualquier actividad de intermediario para las personas afectadas por la maternidad de sustitución debe estar prohibida, así como todas las formas de publicidad relacionadas con ella. Sin embargo, los Estados pueden, en casos excepcionales previstos en su legislación nacional, proporcionar, sin excepción al párrafo 2 de este Principio, que un médico o un establecimiento puede fertilizar a una madre sustituta mediante el uso de técnicas artificiales de procreación, siempre que la madre sustituta no obtiene ningún beneficio material de la operación; y que la madre gestante pueda, al nacimiento, elegir quedarse con el niño [...]. (Mennesson, Labassee, 2018).

Por su parte, el Congreso del estado de Tabasco en la justificación de la reforma consideró como literatura el trabajo de Fernando Alarcón, "El Negocio de maternidad por sustitución en la gestación", obtenido de las memorias del Primer Seminario Franco-Andino de Derecho y Bioética de- 
sarrollado en Bogotá por el Centro de Estudios sobre genética y Derecho de la Universidad Externado de Colombia en el año 2003; igualmente, el trabajo Maternidad Subrogada de agosto de 2008, publicado por el Centro de Documentación, Información y Análisis del Congreso de la Unión, en el que se señala que la filiación no es la única cuestión que se plantea a partir de la posibilidad de escisión de la procreación con respecto a la sexualidad. Los gametos masculino y femenino, el embrión y la gestación, son elementos separables e intercambiables que adquieren valor de uso para otras personas, que como pacientes, médicos, investigadores o como otro tipo de usuarios, están interesados en utilizarlos. Con esto no solo cobra relevancia su estatus jurídico como partes o funciones del cuerpo humano, sino que se convierten en objeto de apropiación y de intercambio. A partir de esto no se trata simplemente del problema de que, puntual o clandestinamente, se comercie con materiales humanos y se pague por ellos, aunque puede ser una de las manifestaciones más preocupantes. No se trata meramente de que la distribución o producción de estos materiales esté más o menos mercantilizada, tampoco de que existan unas fuerzas y mecanismos de mercado que los atraigan a su dinámica. El hecho significativo es que estos materiales se puedan constituir en bienes (Lema, 1999, p. 101).

Frente a la cosificación mercantil del menor puede atribuirse cierta analogía entre la adopción fraudulenta y las formas de atribuir la relación paterno-filial derivada del acto reproductivo de la gestación por sustitución, con problemáticas identificadas cuando se dan fallas de tipo legislativo que no implican ningún obstáculo; en este punto la Corte Interamericana de Derechos Humanos ha señalado que la adopción debe lograrse mediante la intervención judicial para controlar su ejecución, ya que es importante que sea "un acto tendiente al bienestar del niño" y la falta de control sobre ella puede dar lugar a abusos y acciones ilícitas (OC17/2002, pp. 40-41).

\section{Necesidad}

Existen argumentos pausibles para sostener en Tabasco, el registro del recién nacido por los padres de intención mediante intervención judicial (adopción) es una medida legislativa necesaria (equilibrada) entre los intereses públicos, privados y peligros derivados de la gestación por sustitución considerando el espectro de ser la gestación por sustitución un acto jurídico normativo complejo estructurado por actos de la vida privada, actos de la administración pública, actos legislativos, hechos naturales, con autonomía propia pero todos juntos dirigidos a la producción de un efecto final (Pérez, 2017, pp. 62-63).

Un punto esencial de partida es la doctrina dada en la sentencia del Tribunal de Estrasburgo en los casos franceses: 
[...] los riesgos asociados con las nuevas técnicas en un campo tan sensible como la procreación médicamente asistida, deben tomarse seriamente en consideración y que en primer lugar el legislador doméstico debe evaluar estos riesgos después de haber calibrado cuidadosamente los distintos intereses públicos y privados involucrados y los peligros a los que pudiera hacerse frente[...]. (Mennesson, Labassee, 2018).

Doctrina que puede ser encajada con la establecida por la Corte Suprema de los Estados Unidos de América: "[...] el Estado puede limitar más severamente los derechos de los niños que los adultos en nombre de la seguridad pública y con el propósito de alentar su crecimiento y desarrollo [...]" (Prince v. Massachusetts, 1944).

La Corte Interamericana de Derechos Humanos (Opinión Consultiva número 5, 1985, párrs. 46 y 79) y la Corte Europea de Derecho Humanos (Sunday Times c. royaume-Uni, 1979, pp. 34-35) han señalado que necesario no es sinónimo de indispensable y que para que una restricción sea necesaria, entre las alternativas debe optarse por la que restrinja en menor escala el derecho protegido. El examen de necesidad de la medida legislativa implica corroborar, en primer lugar, si existen otros medios con un grado de idoneidad igual o superior para lograr los fines que se persiguen, y en segundo lugar determinar si estas alternativas intervienen con menor intensidad el derecho fundamental afectado (Bernal, pp.742-750).

En la legislación de Tabasco no se distingue un escenario similar en donde el legislador hubiere considerado adecuadas otras medidas, en ese tenor la búsqueda de medios alternativos se pretende acotar analizando las variantes en el derecho comparado, tanto en el plano legislativo como en el jurisprudencial, sin que ello signifique que el legislador se encuentre obligado a regular de forma idéntica, toda vez que las restricciones deben ponderarse en cada caso en particular y debe atenderse al margen de apreciación del estado de Tabasco para definir el orden público y la forma de reconocimiento de la filiación. Legitimación estatal que se justifica toda vez que en el tema de la gestación por sustitución concurren en forma legítima concepciones jurídicas, filosóficas, morales, éticas, religiosas, ideológicas, científicas y de otros órdenes, sin existir un consenso interestatal de interpretación acorde a fuentes formales del derecho para la integración de la norma jurídica (Vio, 2012).

Además, el argumento de discriminación por razón de filiación no exige que el ordenamiento jurídico de Tabasco deba regular en forma idéntica derivada de la gestación por sustitución. El legislador goza de cierto margen de libertad para atribuir el carácter de relación paterno filial a determinadas relaciones distintas de la paternidad o maternidad biológicas, derivadas del matrimonio o concubinato, de la adopción o del consentimiento a la fecundación con contribución de donante, prestado por el cónyuge o conviviente de la mujer que se somete al tratamiento de reproducción asistida (Saraza, 2015). 
La legislación de Tabasco no anula la inscripción de la filiación, sino que obliga a cumplir la formalidad de la adopción, la cual puede ser criticada para el caso de formalizar la filiación biológica, empero, si el legislador determinó la intervención judicial posterior al nacimiento, esa elección puede considerarse menor al poder elegirse la impugnación de la paternidad biológica en forma contenciosa. En el mismo tenor, en los casos franceses, el Tribunal Estrasburgo examina si la injerencia de Francia, prevista en la ley y que responde a fines legítimos y subraya que, consideradas las delicadas cuestiones éticas que suscita este tema y la falta de consenso sobre el mismo en Europa, los Estados deben disponer de un amplio margen de apreciación en sus opciones relativas a la gestación por sustitución. Como todos los derechos, precisa el Tribunal Supremo Español, el derecho a crear una familia no es ilimitado y no incluye la facultad de establecer lazos de filiación en cualquier forma, siempre que esta falta de reconocimiento no sea contraria a las exigencias constitucionales (Saraza, 2015), ni en la especie al orden público de Tabasco y además respete las exigencias convencionales en materia de derechos humanos y de la infancia.

Legislación internacional. La gestación por sustitución está expresamente prohibida en Alemania, Arabia Saudita, Austria, Bélgica, China, España, Estonia, Francia, Hungría, Holanda, Islandia, Italia, Japón, Moldavia, Noruega, Pakistán, Suecia, Suiza, Turquía; en Estados Unidos: Indiana, Nebraska; en México: Coahuila y Querétaro. No existe regulación en Argentina, Brasil, Chile, Chipre, Finlandia, Guatemala, Irlanda, Luxemburgo, Malta, Panamá, Polonia, San Marino y en el resto de los Estados de la República Mexicana (Mennesson, 2018, párr. 41; Labassee, 2018, párr. 32; Lamm, 2012, pp. 71, 102, 118, 125, 126, 127, 128, 181, 185; Lamm, 2013, p. 5; Verschelden, 2013, p. 49; Nadia de Araujo, 2013, p. 85; Hou, 2013, p. 93; Perreau-Saussine, 2013, p. 119; Gössl, 2013, p. 131; Nagy, 2013, p. 175; De Alcantara, 2013, p. 247; Orejudo, 2013, p. 347; Snyders, 2013, p. 387; Sloan, 2016; Martiny, 2016; Szeibert, 2016; Cubeddu, 2016; Lamarca, 2016; Schwenze, 2016; Orücü, 2016).

En relación con la inmediatez, intervención judicial e incidencia del parámetro genético en el registro del nacimiento, en las legislaciones donde expresamente se permite, se agrupan tres supuestos:

A. Israel, Reino Unido y Australia impiden el registro administrativo del recién nacido por los comitentes con independencia de ser los padres genéticos, imponen: I. La intervención judicial posterior al nacimiento para establecer la filiación; II. Un periodo de espera para asignar esa filiación; y III. La posibilidad de no reconocer relación parental con los padres de intención con independencia del parámetro genético, ello derivado del interés del menor o el arrepentimiento de la gestante o el desinterés de los comitentes al dejar prescribir el plazo para solicitar la orden parental (Shalev, 2011, p. 182; Lamm, 2012, pp. 131-148, 159; Levush, 2012, p. 
10-11; Keyes, 2013, pp. 25-48; Shakargy, 2013, pp. 231-246; Wells-Greco, 2013, pp. 367-386; Douglas, 2016).

A. En el caso de Israel la supervisión estatal es de tal relevancia que los procedimientos de fertilización in vitro solo pueden realizarse en instituciones públicas de forma gratuita (Shnit, 1985, p. 155; Nahmani, 1995, párr. 16, 17, 18; Sharon, 2013, p. 239).

B. Grecia, Ucrania, Portugal, Sudáfrica, Rusia y Canadá con excepción de la provincia de Quebec, prevén una intervención tanto administrativa como judicial anterior al nacimiento para el asentamiento del menor ante el Registro Civil. El principal efecto de la intervención estatal anterior al parto es la generación de la presunción legal de la filiación genética de los comitentes o al menos de uno de ellos, el varón regularmente, con la donación anónima del ovocito, salvo Portugal que prohíbe el anonimato. Presunción que se justifica ante la prohibición de que la gestante aporte su material genético, consecuentemente se omite la paternidad derivada del parto y de quien demuestre nupcias. Generalmente se excluye el acceso al varón independiente, parejas heterosexuales en que ambos son infértiles o familias homoparentales masculinas (Rokas, 2013, pp. 143; Khazova, 2013, p. 311; Slabbert, 2013, p. 325; Druzenko, 2013, p. 357; Khazova, 2016).

En Grecia la gestante no puede aportar su material genético; esta y los comitentes deben ser ciudadanos griegos o residentes permanentes, la maternidad por la gestante puede ser impugnada en un plazo de seis meses posteriores al nacimiento, y existe restricción de acceso al varón independiente (Lamm, 2012, pp. 150-153; Zervogianni, 2012, p. 15; Rokas, 2013, pp. 143-166).

Ucrania no otorga nacionalidad a los hijos de extranjeros nacidos en su territorio, la gestante no puede aportar su material genético, acceso exclusivo a parejas heterosexuales casadas (Lamm, 2012, pp. 174-178; Druzenko, 2013, pp. 357-365).

En Portugal la gestante no puede aportar su material genético, exclusiva para parejas heterosexuales y parejas homoparentales femeninas y se prohíbe la donación anónima de gametos (Assembleia da República Portuguesa, 2016) (Lamm, 2012, pp. 130-131).

En Sudáfrica los padres de intención deben ser ciudadanos o residentes, se excluye a modelos familiares donde ambos son infértiles, la gestante no puede aportar su material genético y puede impugnar la maternidad en un plazo de 60 días de haber aportado su carga gamética, acreditándose la libertad de la decisión y las conciencias de las consecuencias (Lamm, 2012, pp. 164-170; Slabbert, 2013, pp. 325-345). 
En Canadá no existe restricción a extranjeros o modelo familiar, se permite la donación de gametos tanto masculino como femenino (Government of Canada, 2004) (Lamm, 2012, pp. 148-153).

En Rusia, se restringe el acceso al modelo familiar monoparental masculino monoparental femenino infértil y homoparentales, la gestante no aporta su material genético, los gametos deben proceder de la pareja y en su defecto de un donante (Khazova, 2013, pp. 311-324; Khazova, 2016).

C. En los Estados Unidos de Norteamérica: California, Connecticut, Delaware, Maine, Nevada, Nuevo Hampshire y el Distrito de Columbia, se prevé una intervención exclusivamente judicial anterior al nacimiento para el registro del menor mediante sentencia judicial, lo que resulta relevante dado el efecto de la "cosa juzgada". El principal efecto de la intervención estatal anterior al parto es la generación de la presunción legal de la filiación de intención de los comitentes con independencia de la relación genética con el menor, no existe restricción a extranjeros ni a ningún modelo familiar, se permite la donación de gametos tanto masculino como femenino, en algunos estados como California ni siquiera existe legislación expresa y la filiación se determina judicialmente con base en precedentes (Lamm, 2012, pp. 185-192; Snyder, 2013, pp. 387-396).

Lo expuesto denota, por una parte, un ascenso sobre la necesidad de la intervención estatal en el acto reproductivo de la gestación por sustitución para la determinación paterno filial vía administrativa, judicial o ambas. De otra parte, se evidencia una falta de consenso para determinar la necesidad de que dicha intervención sea anterior o posterior al parto, en tanto que cada alternativa deriva de una política pública diversa para determinar las presunciones legales en relación a los comitentes que puede ser dividida en tres grupos:

1. En el primer grupo de legislaciones extranjeras, se mantiene como funcional un sistema de presunciones legales sobre un concepto que se identifica como "filiación biológica" que reconoce el parto y las nupcias como causa generadora de la relación paterno filial. La trascendencia del parto entraña una especial valoración de la función de la gestación que se confirma con notas distintivas: el reconocimiento judicial de la filiación es posterior al parto, la existencia de un periodo de reflexión para la gestante y la facultad gestante puede retener al menor.

Evidente es que la legislación de este primer grupo de países resulta más inclusiva que en Tabasco: al limitar o desconocer el parentesco genético a un periodo de reflexión con posibilidad de arrepentimiento de la gestante para mantener la custodia del recién nacido o bien la prescripción del plazo para solicitar la orden parental. 
Asimismo, se hace notar que el orden público de los países del primer grupo, sobre la mercantilización del infante que se tutela a través de: la posibilidad de la determinación judicial para no otorgar filiación a los comitentes con base en el interés del menor; la exclusión a extranjeros o; por contradecir la política pública al realizar un acuerdo comercial o sin tener problemas de infertilidad.

1. El segundo grupo construye una figura que se distingue como "filiación genética" que reconoce los adelantos científicos en materia de reproducción, lo cual permite separar el hecho del parto y el acto de demostrar nupcias para determinar que padre es quien aporta sus genes. Generándose un sistema de presunciones paterno filiales sentadas en el imperativo público -para que los padres de intención aporten su carga gamética o al menos uno de ellos- debido a la infertilidad el otro, de ahí que se admita la impugnación después del parto de la maternidad de la gestante de haber aportado su perfil genético, ello como grado de sanción por no acatar imperativo enunciado.

2. En el tercer grupo, los Estados de California, Connecticut, Delaware, Maine, Nevada, Nuevo Hampshire y el Distrito de Columbia, la paternidad se argumenta en lo que se ha denominado como "filiación de intención", la cual impera sobre la supremacía genética. Conceptuándose que la paternidad de intención no es una privación de los derechos constitucionales de la gestante ni ofende a la Constitución estatal o federal ni a la política pública (Johnson contra Calvert, 1993). Además, el estatuto que rige la inseminación artificial que hace a un esposo el padre legítimo de un niño que no tiene relación con él se aplica tanto al cónyuge de la gestante como de la comitente, el cónyuge de esta última es el padre legal del recién nacido, incluso si prometió asumir toda la responsabilidad por el cuidado del menor. A pesar de que los padres legales no estén relacionados biológicamente con el recién nacido, siguen siendo sus padres legítimos debido a su papel iniciador como padres intencionados en su concepción y nacimiento, si significativamente se correlaciona con los mejores intereses del niño (Buzzanca contra Buzzanca, 1998).

Jurisprudencia internacional. En Francia existen como referentes emblemáticos las sentencias emitidas por la Corte Europea de Derechos Humanos sobre los asuntos: Mennesson y Labassee de junio de 2014, Foulon y Bouvet de julio de 2016. En los cuatro juicios uno de los padres de intención aportó su material genético, en los dos primeros se pedía la transcripción de la sentencia estadounidense que establecía la filiación del menor en relación con los comitentes, anulándose la inicial inscripción para posteriormente impedírseles jurisprudencialmente la vía del reconocimiento y la adopción. La diferencia con los últimos dos estriba en que se solicitaba el establecimiento de la filiación del menor con los padres de intención por la vía de la posesión de estado de hijo. Francia negó, anuló 
e impidió por todo medio administrativo y judicial el reconocimiento de la filiación derivada del acuerdo de gestación por sustitución establecida en el extranjero, por violar el orden público internacional francés. La Corte Europea de Derechos Humanos estimó que no se había violado el respeto a la vida familiar de los solicitantes, en tanto que habían podido vivir como familia de facto, empero sí consideró violado el derecho a la vida privada de los menores al habérseles impedido en forma absoluta el establecimiento de la filiación con los padres de intención, máxime que por lo menos uno de ellos era el biológico.

Antes de la publicidad del primer caso francés y después del italiano Paradiso y Campanelli, en España, el 6 de febrero de 2014, el Tribunal Supremo se pronunció, por primera vez, en un caso de gestación por sustitución internacional que involucra los derechos de dos menores y de un matrimonio conformado por dos personas de sexo masculino. La sentencia confirmó lo decidido en las instancias previas (cancelar la inscripción de nacimiento) y, consecuentemente, dejó a estos menores sin la nacionalidad española y sin los beneficios que devienen de su titularidad. Lo resuelto en esta sentencia fue luego confirmado por el Pleno de la Sala de lo Civil del Tribunal Supremo en un auto del 2 de febrero 2015, recurso número 245/2012 (Flores, 2014, pp. 71-89). El Pleno recalcó que la sentencia protege el interés de los menores pues permite la fijación de las relaciones paterno filiales mediante la determinación de la filiación biológica paterna mediante impugnación judicial y la formalización de las relaciones familiares de "facto" mediante la adopción o el acogimiento, protegiendo en todo momento la unidad familiar en que puedan estar integrados los menores (Durán, 2012, pp. 268-269). Instando al Ministerio Fiscal para que adoptara las medidas pertinentes, en el sentido indicado, para la protección de las niñas y niños.

Hecho el esbozo anterior, en relación con la necesidad de la intervención legislativa en Tabasco, es menester puntualizar dos orientaciones con relación al caso de Tabasco.

La primera, la intervención estatal, sea judicial o administrativa, anterior o posterior al parto, obedece a un sistema de presunciones legales basado en los conceptos de filiación: biológica, genética o de intención. El modelo a comparar con el orden público de Tabasco es el intitulado "biológico" que parte del hecho del parto y del acto de nupcias, el cual es compartido por Israel, Reino Unido y Australia, que han definido la intervención judicial necesaria después del parto para posteriormente asentar la filiación a los comitentes.

La segunda, el dialogo expreso que se puede establecer entre el caso de la sentencia de Tabasco y el discurso expreso de la Corte Europea de Derechos Humanos y el Pleno de la Sala de lo Civil del Tribunal Supremo Es- 
pañol, se focaliza en la suprainclusividad del orden público francés hacia la identidad del menor. La desproporción así calificada por ambos entes judiciales atiende a una restricción absoluta que no se permite el reconocimiento de la filiación entre comitentes y las niñas nacidas a través de gestación por sustitución por ningún medio (transcripción de actas de nacimiento extranjeras, filiación biológica, adopción, posesión de estado). Lo que conduce a obstaculizar tanto el reconocimiento como el establecimiento en derecho interno de su relación de filiación, incluso respecto del padre biológico, actuando así el Estado francés ha ido más allá de lo que permite su margen de apreciación.

\section{Proporcionalidad e inmediatez en el caso concreto}

La categoría de proporcionalidad entraña ponderación entre una colisión de derechos en un caso en particular (Barak, 2012, p. 343), se compara el grado de intervención en el derecho a la vida privada del menor en la vertiente del registro inmediato de su nacimiento, que supone la medida legislativa de instar un procedimiento de adopción frente al grado de realización del fin perseguido sobre la protección del interés del niño y el orden público, para balancear los beneficios que cabe esperar de una limitación desde la perspectiva de los fines que se persiguen con los costos que necesariamente se producirán para el derecho afectado (Bernal, 2007, p.763).

La Corte Europea de Derechos Humanos en ningún caso afirma que cualquier afectación parcial y a priori a la filiación del menor puede suponer una vulneración de su derecho a la vida privada (Mennesson, párr. 84, Labassee, párr. 63), sino que tal afectación desequilibrada de los intereses legítimos que puede perseguir el estado existe en estas condiciones del Derecho positivo francés, por establecer una absoluta imposibilidad de que su ordenamiento jurídico reconozca cualquier vínculo de filiación entre los comitentes y el niño, no solo por la imposibilidad de transcribir el acta de nacimiento norteamericana, sino muy especialmente, por impedir que se reconozca la filiación biológica paterna, además de la filiación por posesión de estado o por adopción (Durán, p. 13). En esa lid la excepción del orden público entraña una necesidad de procurar equilibrio justo entre el interés de la comunidad en lograr que sus miembros cumplan con la elección efectuada democráticamente en su seno y el interés de los demandantes, incluido el interés superior del niño.

Lo que señala expresamente el Tribunal de Estrasburgo es que a los menores hay que reconocerles un estatus definido, una identidad cierta. Ese estatus debe ser fijado conforme a las normas esenciales del orden público en cuestión sobre filiación y estado civil.

Una alternativa plausible para reconocer ese estatus definido de identidad cierta es con intervención judicial posterior al parto por vía de la adopción, la cual incorpora al adoptado a una familia como hijo legítimo, 
confiriéndole los apellidos de los adoptantes y los mismos derechos, obligaciones y parentesco que la filiación consanguínea (Artículo 398, Código Civil para el estado de Tabasco). Las ventajas de esta opción legislativa derivan de sus efectos con relación a la seguridad jurídica: por un lado, se desvanece el lazo de parentesco con la gestante derivada del parto, incluso si hubiera aportado su carga gamética; por otro lado, es más benigna que otras legislaciones puesto que no se impone un plazo de espera para el registro del menor, salvo el mayor interés del menor, no existe posibilidad de no quedar reconocida la relación parental con los comitentes por el arrepentimiento de la gestante; consecuentemente, no se trata de una disposición "suprainclusiva", siendo evidente que es una intervención poco gravosa que se orienta a prohibir o regular en ciertas condiciones el ejercicio de ese derecho y no se extiende más más allá de lo necesario (Schauer, 2004, pp. 31-34). En atención a que a través de un procedimiento no contencioso el Estado tiene la oportunidad de proteger los intereses del infante y del orden público en virtud de una tutela judicial, la representación del Ministerio Público y en su caso de los organismos para el desarrollo integral de la familia. En esas condiciones la legislación de Tabasco no va mas allá de lo que le permite su margen de apreciación.

Un segundo punto de análisis a considerar en la tópica de necesariedad es la interpretación del término inmediatez. El artículo 4 de la Constitución Política de los Estados Unidos Mexicanos, en su octavo párrafo, dispone el enunciado: "[...] Toda persona tiene derecho [...] a ser registrado de manera inmediata a su nacimiento $[\ldots]$ ".

Diversos organismos, entre ellos, el Centro de Investigación Innocenti ${ }^{2}$, el Observatorio Social de la Niñez y Adolescencia ${ }^{3}$, ambos del Fondo de las Naciones Unidas para la Infancia, el Departamento de Asuntos Económicos y Sociales de las Naciones Unidas ${ }^{4}$ y especialistas ${ }^{5}$, han atribuido sentido al concepto de inmediatez en el registro de nacimiento: significa que los Estados deben poner el registro de nacimiento al alcance y a dis-

2 "[...] significa que los Estados deben poner el registro de nacimiento al alcance y a disposición de todos los niños[...]" (Inoccenti Digest, 2002). El tema principal gira entorno al no registro de los menores por la falta de conciencia del valor de la inscripción el nacimiento, donde no se organizan campañas públicas, donde la red de registros civiles es inadecuada o donde el costo de la inscripción de los niños es prohibitivo.

3 Definió la variable "registro tardío". De ese modo se estipularon los siguientes niveles de inscripción: normal: primer mes de vida; retraso bajo: entre los 2 y 11 meses de edad; retraso medio: entre 1 y 4 años de edad; retraso moderado: entre 5 y 11 años de edad (edad escolar); retraso alto: entre los 12 y 17 años de edad (adolescencia); retraso grave: a los 18 o más años de edad (edad adulta) (Tamargo, 2007).

4 En razón el tiempo la mayor parte de los Estados consideran un registro tardío, el retraso de más de 30 días para inscribir el nacimiento. (Departamento de Asuntos Económicos y Sociales de las Naciones Unidas, División de Estadísticas, 1998).

5 La expresión de inmediatez implica una urgencia y la necesidad de actuar en lapso razonablemente breve (Santos, 1997). 
posición de todos los niños con una conciencia de urgencia y necesidad de actuar en un lapso razonablemente breve; considerándose un registro tardío con escala gradual: baja, media, moderada, alta y grave después del primer mes del nacimiento.

Siguiendo el mismo discurso del Tribunal Supremo Español, se puede asumir que las molestias e inconvenientes para los comitentes (y en menor medida para el recién nacido que por su corta edad no será consciente siquiera de la situación) puede suponer la situación provisional que se produzca por el establecimiento de la filiación resultante de la aplicación de las normas del ordenamiento jurídico de Tabasco, la adopción, no alcanzan una entidad suficiente como para considerar que se produce el desequilibrio vulnerador del derecho a la vida privada de los niños, en su aspecto de fijación de una identidad determinada.

Se trata de una situación temporal que puede tener una duración razonablemente breve (determinación de la filiación paterna respecto del progenitor biológico y en su caso de su pareja), y el Estado de Derecho provee de suficientes medios para evitar perjuicios a los menores durante esta interinidad, siguiendo el criterio de protección del núcleo familiar "de facto". Como lo estimó la Corte Europea de Derechos Humanos en los casos Mennesson y Labassee al sostener: los obstáculos con los cuales se han encontrado los demandantes no son insuperables y los demandantes no se han visto impedidos de disfrutar en Francia del derecho al respeto de su vida familiar.

Se ha acreditado que padres e hijas se han podido establecer juntos en Francia poco después del nacimiento, que viven juntos en una situación globalmente comparable a aquella en las que viven otras familias y que no se ha estimado que exista riesgo de que las autoridades decidan separarles con motivo de su situación respecto del derecho francés. Además, como consecuencia de un examen del caso concreto, los jueces franceses han estimado que las dificultades prácticas con las que se han encontrado los recurrentes no han excedido los límites que impone el respeto a la vida familiar. En consecuencia, según el Tribunal de Estrasburgo, se ha alcanzado un justo equilibrio entre los intereses de los recurrentes y los del Estado por lo que se refiere a su derecho al respeto a la vida familiar.

\section{RESULTADOS}

En el caso de Tabasco el acta de nacimiento o certificación registral que se expida basada en la sentencia del juicio de amparo (sosteniéndose la constitucionalidad del acto por la autoridad versus la pretensión de los solicitantes) en relación al registro inmediato de un menor con inmediatez a su nacimiento sin agotar instancias judiciales previas, no será reflejo secundario de una diversa resolución judicial del fuero común (juzgado familiar) como mera formalización de un procedimiento de adopción ple- 
na, donde no existe una contienda entre partes.

Se trata entonces de una interpretación de un tribunal que detenta el control concentrado (y no difuso) de constitucionalidad en México. Resolución de interpretación constitucional que implícitamente marca pauta y es una herramienta para el legislador y el ejecutivo local para el diseño de la política pública en relación con la inmediatez del registro de nacimiento de un niño sin necesidad de agotar instancias judiciales previas sobre la preponderancia de la parentalidad biológica y la implícita omisión de las presunciones del parto.

En forma expresa en la resolución judicial del caso de Tabasco se dio contenido al perímetro material del interés superior del menor en comunidad con una paternidad de intención biológica derivada de un contrato de gestación por sustitución y el orden público; no obstante, el hecho de que el legislador tenga como finalidad impedir que se comercialice con la vida humana.

En ese contexto la decisión del juez de distrito constituye la extensión de la delimitación perimetral del derecho a la identidad, siendo más garantista e implícita orienta la política pública a un nuevo mínimo exigible, en el sentido de ir más allá de los discursos europeo e interamericano de derechos humanos que han definido ilegítima la intervención a la vida privada del menor, impedir el establecimiento de su filiación correspondiente que ha definido como mínimo el acceso al registro de la realidad biológica y en su caso la realidad social de un menor mediante el reconocimiento, adopción o posesión de estado de hijo.

\section{CONCLUSIONES}

La figura, principio, tópica, técnica o doctrina del margen de apreciación nacional, es un modelo de aproximación compartido por las cortes Europea e Interamericana de Derechos Humanos, el cual demarca la concepción en que los Estados partes limitan los derechos reconocidos en las respectivas convenciones.

La Corte Europea de Derechos Humanos ha permitido la limitación estatal de los derechos, reconociendo que el margen de apreciación (discrecionalidad) es consustancial al principio democrático y a la soberanía nacional de los Estados partes, puesto que la valoración del interés colectivo superior en cada sociedad resulta una tarea política sensible y menos jurídica; empero, dicha individualidad descansa en una presunción de que la decisión y su consecuente regulación opera de manera transparente y permite la participación efectiva en una democracia consolidada. En una intención de una teoría naturalizada de los derechos humanos de contribución filosófica útil que no necesariamente que contempla un sistema normativo positivo con diversos niveles de generalización (Aguado, pp. 46-47). 
En el ámbito interamericano se habla de la necesidad de un control más garantista, frente a una crónica y sistemática violación de derechos humanos, donde la aplicación del derecho es insuficiente y el margen de apreciación es marginado y no frecuente.

Un punto de encuentro entre ambos sistemas es el parámetro de proporcionalidad racional, en Europa la verificación para no rebasar el margen de apreciación en las limitaciones estatales y en América la compatibilidad de las limitaciones con la Convención.

Europa ha sido permisiva en el margen de los países para determinar lo que es de utilidad pública en materia económica y social, mientas que América vincula los derechos sociales con los civiles y políticos.

La autoridad que ejercen los tribunales internacionales constituye una gobernanza global que refracta en la construcción normativa (más allá del Estado, antes de él o incluso contra la ley de aquél) y en la redistribución del poder y de los recursos sobre órganos colectivos con legitimación democrática que ordinariamente definen presupuesto y prioridad de aplicación. Erigiendo un constitucionalismo supraestatal o constitucionalismo sin Estado. Lo que entraña la consideración de la relación de pluralidad jurídica entre el Derecho Constitucional y el Derecho Internacional Público, que sirve de guía de interacción de la función de los jueces nacionales en un Estado constitucional de cooperación y solidaridad, más allá de la voluntad estatal frente a la asunción de obligaciones internacionales.

En el discurso del derecho a la identidad, precisamente en el enunciado constitucional: "[...]Toda persona tiene derecho[...] a ser registrado de manera inmediata a su nacimiento[...] " (artículo 4 de la Constitución Política d ellos Estados Unidos Mexicanos), el alcance del término "inmediatez" se interpreta en un sentido de brevedad razonable y no con base en el significado literal.

El legislador goza de un cierto margen de libertad para atribuir el carácter de relación paterno-filial a determinadas relaciones distintas de la paternidad o maternidad biológicas derivadas de la gestación por sustitución, el derecho a crear una familia no es ilimitado y no incluye la facultad de establecer lazos de filiación en cualquier forma, siempre que esta falta de reconocimiento no sea contraria a las exigencias constitucionales y que procure un equilibrio entre el interés de la comunidad en lograr la elección efectuada democráticamente, los peligros derivados de la gestación por sustitución (interés público), el interés del comitente y del menor (intereses privados); la construcción de diversos conceptos de filiación: biológica, genética o de intención; la intervención judicial y su funcionalidad en la interpretación de la noción de inmediatez en el registro de nacimiento. 


\section{REFERENCIAS}

Aguado Romero, Gabriela y otro. (2016). Derecho administrativo. Un ámbito de respeto, promoción, protección y garantía de los derechos humanos. México: Tirant lo blanch.

Alarcón Rojas, Fernando. (2003). El Negocio de maternidad por sustitución en la gestación, en González de Cansino, Emilssen (coord.), Memorias del Primer Seminario Franco-Andino de Derecho y Bioética. Bogotá: Centro de Estudios sobre genética y Derecho-Universidad Externado de Colombia.

Alexy, Robert. (2007). Teoría de los derechos fundamentales, trad. Carlos Bernal Pulido. Madrid: Centro de Estudios Políticos y Constitucionales.

Álvarez Ugarte, Ramiro. (2012). Dinámicas de acción y reacción en la Corte Suprema: una mirada al caso FAL sobre aborto no punible. Jurisprudencia Argentina, 11/7/12, JA 2012-III, fascículo n. 2. 27 de septiembre de 2018, de Academia Sitio web: https://www.academia.edu/4145138/2012 Din\%C3\%A1micas de Acci\%C3\%B3n_y_Reacci\%C3\%B3n_Ante_la_Corte_Suprema? auto=download

Asamblea General de la Organización de los Estados Americanos (OEA). (1988). Protocolo Adicional a la Convención Americana sobre Derechos Humanos en Materia de Derechos Económicos, Sociales y Culturales "Protocolo De San Salvador". 27 de octubre de 2018, Sitio web: http://www.oas.org/juridico/spanish/Tratados/a-52.html

Assembleia da República Portuguesa. (2017). Lei 25/2016. 28 de septiembre de 2018, de Diário da República n. ${ }^{\circ} 160 / 2016$, Série I de 2016-08-22 Sitio web: https://dre.pt/web/guest/pesquisa/-/ search/75177806/details/maximized

Barak, Aharon. (2012). Proportionality. Constitutional Rights and their Limitations, trad. Doron Kalir. Nueva York: Cambridge University Press.

Bernal Pulido, Carlos. (2007). El principio de proporcionalidad y los derechos fundamentales. Madrid: Centro de Estudios Políticos y Constitucionales.

Centro de Investigaciones Innocenti. (2002). El Registro de Nacimiento: El derecho a tener derechos. Inoccenti Digest, N. 9-marzo de 2002, pp. 3 y 11. 28 de septiembre de 2018, De Fondo de Naciones Unidas para la Infancia Sitio web: https://www.unicef-irc.org/publications/pdf/digest9s.pdf.

Comité Consultatif National d'Ethique pour les sciences de la vie et de la santé. (1984). Avis sur les problèmes éthiques nés des techniques de reproduction artificielle. Rapport. $\mathrm{N}^{\circ} 3$ - 23 octobre. 27 de septiembre de 2018. Sitio web: http://www.ccne-ethique.fr/sites/ 
default/files/publications/avis003.pdf

Comité Consultatif National d'Ethique pour les sciences de la vie et de la santé. (2005). Accès aux origines, anonymat et secret de la filiation. $\mathrm{N}^{\circ} 90$ - 24 novembre. 27 de septiembre de 2018. Sitio web: http:// www.ccne-ethique.fr/sites/default/files/publications/avis090.pdf.

Comité Consultatif National d'Ethique pour les sciences de la vie et de la santé. (2010). Problemes ethiques souleves par la gestation pour autrui (GPA). $\mathrm{N}^{\circ} 110$ - 1er avril 2010. 27 de septiembre de 2018. Sitio web: http://www.ccne-ethique.fr/sites/default/files/publications/avis_110.pdf.

Congreso de la Unión. (2016). Constitución Política de los Estados Unidos Mexicanos. 28 de octubre de 2018, de Cámara de Diputados. Sitio web: http://www.diputados.gob.mx/LeyesBiblio/htm/1.htm

Corte Europea de Derechos Humanos. (1979). SUNDAY TIMES c. ROYAUME-UNI. 27 de Julio de 2018, Sitio web: file:///D:/DATOS\%20 USUARIO/Downloads/AFFAIRE\%20SUNDAY\%20TIMES\%20 c.\%20ROYAUME-UNI\%20(N_\%201).pdf

Corte Europea de Derechos Humanos. (2014). Labassee c. France. 27 de Julio de 2018, Sitio web: https://hudoc.echr.coe.int/eng\#\{\%22itemid\%22:[\%22001-145180\%22]\}

Corte Europea de Derechos Humanos. (2014). Mennesson c. France. 27 de Julio de 2018, Sitio web: https://hudoc.echr.coe. int/eng\#\{\%22display\%22:[2],\%22languageisocode\%22:[\%22FRE\%22],\%22appno\%22:[\%2265192/11\%22],\%22itemid\%22:[\%22001-145179\%22]\}

Corte Interamericana de Derechos Humanos. (1985). Opinión Consultiva OC-5/1985 de 13 de noviembre de 1985, solicitada por el Gobierno de Costa Rica, La Colegiación Obligatoria de Periodistas. 27 de octubre de 2018. Sitio web: http://www.corteidh.or.cr/docs/ opiniones/seriea_05_esp.pdf

Corte Interamericana de Derechos Humanos. (2002). Opinión Consultiva OC-17/2002 de 28 de agosto de 2002, solicitada por la Comisión Interamericana de Derechos Humanos, Condición Jurídica y Derechos Humanos del Niño. 27 de octubre de 2018. Sitio web: http://www.corteidh.or.cr/docs/opiniones/seriea_17_esp.pdf

Cover, Robert M.. (1983). The Supreme Court, 1982 Term-Foreword: Nomos and Narrative. 27 de septiembre de 2018, de Yale Law School Sitio web: https://digitalcommons.law.yale.edu/fss_papers/2705/

Cubeddu Wiedemann, Maria Giovanna. (2016). The Changing Concept of 'Family' and Challenges for Family Law in Italy, en Scherpe, Jens M., European Family Law Volumén II, The Changing Concept of 'Family' and Challenges for Domestic Family Law, University of 
Cambridge and Fellow of Gonville and Caius College, Cambridge, United Kingdom.

De Alcantara, Marcelo. 2013. Japan. En Trimmings, Katarina y otro. (2013). International Surrogacy Arrangements Legal Regulation at the International Level. United Kingdom: Hart Publishing.

Departamento de Asuntos Económicos y Sociales de las Naciones Unidas, División de Estadísticas. (1998). Handbook on Civil Registration and Vital Statistics Systems: Preparation of a Legal Framework. Nueva York: Naciones Unidas.

Díez-Picazo, Luis María. (2005). Sistema de Derechos Fundamentales, $2^{\mathrm{a}}$ ed. Madrid: Thomson Civitas.

Douglas, Gillian. (2016). The Changing Concept of 'Family' and Challenges for Family Law in England and Wales, en Scherpe, Jens M., European Family Law Volumén II, The Changing Concept of 'Family' and Challenges for Domestic Family Law, University of Cambridge and Fellow of Gonville and Caiu s College, Cambridge, United Kingdom.

Druzenko, Gennadiy. (2013). Ukraine. En Trimmings, Katarina y otro. (2013). International Surrogacy Arrangements Legal Regulation at the International Level. United Kingdom: Hart Publishing.

Durán Ayago, Antonia. (2015). Una encrucijada judicial y una reforma legal por hacer: problemas jurídicos de la gestación por sustitución en España. A propósito del auto del Tribunal Supremo de 2 de febrero de 2015. 27 de Agosto de 2018, de Bitácora Millennium, N ${ }^{\circ}$ 2 (2015) Tirant lo blanch Sitio web: http://www.millenniumdipr. com/ba-26-una-encrucijada-judicial-y-una-reforma-legal-por-hacer-la-gestacion-por-sustitucion

Francoz Terminal, Laurence. (2016). The Changing Concept of 'Family' and Challenges for Family Law in France, en Scherpe, Jens M., European Family Law Volumén II, The Changing Concept of 'Family' and Challenges for Domestic Family Law, University of Cambridge and Fellow of Gonville and Caius College, Cambridge, United Kingdom.

Flores Rodríguez, Jesús. (2014). "Gestación por sustitución: más cerca de un estatuto jurídico europeo". Revista de Derecho Privado, Universidad Externado de Colombia, n. 27.

Garzón Valdés, Ernesto. (1989). Algo más acerca del 'coto vedado'. 27 de septiembre de 2018, de Universidad de Alicante Sitio web: https:// rua.ua.es/dspace/bitstream/10045/10845/1/Doxa6_12.pdf

Gobierno Constitucional del Estado Libre y Soberano de Tabasco. (2016). Periódico Oficial, Decreto 265, Suplemento 7654. 12 de julio de 2018. Sitio web: http://periodicos.tabasco.gob.mx/media/periodi- 


\section{cos/7654_sup.pdf}

Government of Canada. (2004). Assisted Human Reproduction Act (S.C. 2004, c. 2). 27 de septiembre de 2018, de Justice Laws Website Sitio web: https://laws-lois.justice.gc.ca/eng/acts/A-13.4/page-2. html\#docCont.

Gössl, Susanne L. (2013). Germany. En Trimmings, Katarina y otro. (2013). International Surrogacy Arrangements Legal Regulation at the International Level. United Kingdom: Hart Publishing.

Government of Canada. (2004). Assisted Human Reproduction Act., de Justice Laws Website Sitio web: https://laws-lois.justice.gc.ca/ eng/acts/A-13.4/page-2.html\#docCont

Gutiérrez Beltrán, Andrés. (2016). El amparo estructural de los derechos, tesis doctoral. 20/11/2017, de Universidad Autónoma de Madrid, Facultad de Derecho, Departamento de Derecho Público y Filosofía Jurídica, Área de Derecho Constitucional. Sitio web: https://repositorio.uam.es/bitstream/handle/10486/676669/gutierrez_beltran_andres_mauricio.pdf? sequence $=1$.

Hou, Zhengxin. (2013). The Peoples's Republico of China. En Trimmings, Katarina y otro. (2013). International Surrogacy Arrangements Legal Regulation at the International Level. United Kingdom: Hart Publishing.

Inoccenti Digest (2002). El Registro de Nacimiento: El derecho a tener derechos. N. 9 marzo de 2002, Fondo de Naciones Unidas para la Infancia, Centro de Investigaciones Innocenti, Florencia Italia, Sitio web: https://www.unicef-irc.org/publications/pdf/digest9s. pdf; pp. 3, 11

Israeli Supreme Court sitting as the Court of Civil Appeals. (1995). Nahmani v. Nahmani. 30 de marzo. Sitio web: http://versa.cardozo. yu.edu/opinions/nahmani-v-nahmani.

Keyes, Mary. (2013). Australia. En Trimmings, Katarina y otro. (2013). International Surrogacy Arrangements Legal Regulation at the International Level. United Kingdom: Hart Publishing.

Khazova, Olga. (2013). Russia. En Trimmings, Katarina y otro. (2013). International Surrogacy Arrangements Legal Regulation at the International Level. United Kingdom: Hart Publishing.

Khazova, Olga. (2016). The Changing Concept of 'Family' and Challenges for Family Law in Russia, en Scherpe, Jens M., European Family Law Volumén II, The Changing Concept of 'Family' and Challenges for Domestic Family Law, University of Cambridge and Fellow of Gonville and Caius College, Cambridge, United Kingdom.

Lamarca Marquès, Albert. (2016). The Changing Concept of 'Family' and 
Challenges for Family Law in Spain and Catalonia, en Scherpe, Jens M., European Family Law Volumén II, The Changing Concept of 'Family' and Challenges for Domestic Family Law, University of Cambridge and Fellow of Gonville and Caius College, Cambridge, United Kingdom.

Lamm, Eleonora. (2012). Gestación por sustitución: ni maternidad subrogada ni alquiler de vientres. España: Publicacions i Edicions de la Universitat de Barcelona.

Lamm, Eleonora. (2013). Argentina, en Trimmings, Katarina y otro. (2013). International Surrogacy Arrangements Legal Regulation at the International Level. United Kingdom: Hart Publishing.

Lema Añón, Carlos. (1999). Reproducción, poder y derecho. Ensayo filosófico-jurídico sobre las técnicas de reproducción asistida, en Arámbula Reyes Alma. (2008). Maternidad Subrogada. 27 de julio de 2018, de Cámara de Diputados Sitio web: http://www.diputados.gob.mx/sedia/sia/spe/SPE-ISS-14-08.pdf

Levush, Ruth. (2012). Israel: Reproduction and Abortion: Law and Policy. 11 de marzo de 2019, de Law Library Of Congress United States Legislative Infomation. Sitio web: http://www.loc.gov/law/help/ israel_2012-007460_IL_FINAL.pdf

Martiny, Dieter. (2016). The Changing Concept of 'Family' and Challenges for Family Law in Germany, en Scherpe, Jens M., European Family Law Volumén II, The Changing Concept of 'Family' and Challenges for Domestic Family Law, University of Cambridge and Fellow of Gonville and Caius College, Cambridge, United Kingdom.

Miranda Camera, Adrián y otro. (2014). El principio de interpretación conforme en el derecho constitucional mexicano. Opinión Jurídica-Universidad de Medellín, Vol. 13, No. 26. De http://www.scielo. org.co/pdf/ojum/v13n26/v13n26a05.pdf.

Nadia de Araujo Vargas, Daniela y otro. (2013). Brazil. En Trimmings, Katarina y otro. (2013). International Surrogacy Arrangements Legal Regulation at the International Level. United Kingdom: Hart Publishing.

Nagy, Cesongor Istvan. (2013). Hungary. En Trimmings, Katarina y otro. (2013). International Surrogacy Arrangements Legal Regulation at the International Level. United Kingdom: Hart Publishing.

Nino, Carlos. (1989). Ética y Derechos Humanos. Un ensayo de fundamentación, $2^{\mathrm{a}}$ ed. Buenos Aires: Astrea.

Oficina Permanente de la Conferencia de la Haya de Derecho Internacional Privado (HCCH). (2010). THE PARENTAGE / SURROGACY PROJECT. 25 de agosto de 2018, de Conferencia de la Haya Sitio 
web: https://www.hcch.net/es/projects/legislative-projects/parentage-surrogacy.

Orejudo Prieto de los Mozos, Patricia. (2013). Spain. En Trimmings, Katarina y otro. (2013). International Surrogacy Arrangements Legal Regulation at the International Level. United Kingdom: Hart Publishing.

Orücü, Esin. (2016). The Changing Concept of 'Family' and Challenges for Family Law in Turkey. En Scherpe, Jens M., European Family Law Volumén II, The Changing Concept of 'Family' and Challenges for Domestic Family Law, University of Cambridge and Fellow of Gonville and Caius College, Cambridge, United Kingdom.

Osuna, Nestor. (2015). Las sentencias estructurales. Tres ejemplos de Colombia, de Justicia constitucional y derechos fundamentales. La protección de los derechos sociales. Colección Konrad Adenauer Sitio web: https://biblio.juridicas.unam.mx/bjv/detalle-libro/4504-justicia-constitucional-y-derechos-fundamentales-la-proteccion-de-los-derechos-sociales-las-sentencias-estructurales-coleccion-konrad-adenauer;

Palacios Alfonso, Marcelo. (1986). Informe de la Comisión Especial de Estudio de la Fecundación In Vitro y la Inseminación Artificial Humanas. 26 de septiembre de 2018, de Congreso de los Diputados Sitio web: http://www.congreso.es/public_oficiales/L2/CONG/ BOCG/E/E 166.PDF

Pérez Chán, Luis Enrique, (2017) Sentencia del 28 de abril, Juicio de Amparo 55/2017-II, Juzgado Segundo de Distrito en el Estado de Tabasco, México

Pérez Fuentes, Gisela María y otros. (2017). La Maternidad Subrogada. México: Tirant lo blanch.

Pérez Fuentes Gisela María. (2017). La dignidad humana y el libre desarrollo de la personalidad en el derecho de familia en México: Principales criterios Jurisprudenciales. no se, de Revista Boliviana de Derecho, ISSN-e 2070-8157, No. 25, 2018, Sitio web: https://dialnet.unirioja.es/servlet/articulo? codigo $=6263397$

Pérez Fuentes, Gisela María. (2018). El Acto Jurídico Normativo. Una Propuesta Normativa ante los Casos Trágicos sobre la Maternidad Subrogada en México, de Actualidad Jurídica Iberoamericana, $\mathrm{N}^{\circ}$. 8, 2018, pp. 59-79 Sitio web: http://roderic.uv.es/bitstream/handle/10550/67249/59-79.pdf? sequence $=1$ \&isAllowed $=y$

Periódico Oficial del Gobierno Constitucional del Estado Libre y Soberano de Tabasco, (2016). Suplemento 7654, número 5136, Decreto 265 Época 6a., Villahermosa, Tabasco, 13 de enero de 2016, pp. 4-16, http://periodicos.tabasco.gob.mx/media/periodicos/7654 
sup.pdf.

Perreau-Saussine, Louis y otro. (2013). France. En Trimmings, Katarina y otro. (2013). International Surrogacy Arrangements Legal Regulation at the International Level. United Kingdom: Hart Publishing.

Prieto Sanchís, Luis. (2003). Justicia constitucional y derechos fundamentales. Madrid: Trotta.

Primera Sala. Suprema Corte de Justicia de la Nación. (2008). Amparo en Revisión 173/2008. 25 de septiembre de 2018, de Semanario Judicial de la Federación Sitio web: http://sjf.scjn.gob.mx/sjfsist/ Paginas/DetalleGeneralScroll.aspx $\mathrm{id}=21489 \&$ Clase $=$ DetalleTesisEjecutorias

Rokas, Konstantinos A. (2013). Greece. En Trimmings, Katarina y otro. (2013). International Surrogacy Arrangements Legal Regulation at the International Level. United Kingdom: Hart Publishing.

Santos Pais, M.. (1997). "The Convention on the Rights of the Child", en Alta Comisionada de las Naciones Unidas para los Derechos Humanos, Instituto de las Naciones Unidas para la Formación Profesional y la Investigación, Proyecto de las Naciones Unidas "Staff College”, Manual on Human Rights Reporting. Ginebra: Naciones Unidas.

Saraza Jimena, Rafael. (2015). Auto ATS 335/2015, 2 de febrero de 2015, recurso 24572013 , casación, auto desestimando nulidad de actuaciones. 27 de septiembre de 2018, de Pleno de la Sala de lo Civil del Tribunal Supremo, Madrid Sitio web: http://www.poderjudicial.es/search/doAction? action $=$ contentpdf\&databasemat$\mathrm{ch}=\mathrm{TS} \&$ reference $=7288332$ \&links $=\% 22245 / 2012 \% 22 \&$ optimi$\mathrm{ze}=20150213 \&$ publicinterface $=$ true

Saúde. (2017). Decreto Regulamentar, 6/2017. 28 de septiembre de 2018, de Diário da República n. ${ }^{\circ}$ 146/2017, Série I de 2017-07-31 Sitio web: http://data.dre.pt/eli/decregul/6/2017/07/31/p/dre/ $\mathrm{pt} / \mathrm{html}$

Schauer, Frederick. (2004). Las reglas en juego: un examen filosófico de la toma de decisiones basada en las reglas en el derecho y en la vida cotidiana. Madrid: Marcial Pons.

Schwenzer, Ingeborg and other. (2016). The Changing Concept of 'Family' and Challenges for Family Law in Switzerland. En Scherpe, Jens M., European Family Law Volumén II, The Changing Concept of 'Family' and Challenges for Domestic Family Law, University of Cambridge and Fellow of Gonville and Caius College, Cambridge, United Kingdom.

Shakargy, Sharon. (2013). Israel. En Trimmings, Katarina y otro. (2013). International Surrogacy Arrangements Legal Regulation at the In- 
ternational Level. United Kingdom: Hart Publishing.

Shalev, Carmel. (2011). Israel, en MONÉGER, Francoise, Gestation pour autrui: Surrogate Motherhood. Francia: Société de legislation comparée.

Shnit, Dan. (1985). Human rights in Israel: Induced Abortion in Israeli Law, en Dinstein, Yoram. Israel Yearbook of Human Rights, Volume 15.

Slabbert, Melodie and other. (2013). South Africa. En Trimmings, Katarina y otro. (2013). International Surrogacy Arrangements Legal Regulation at the International Level. United Kingdom: Hart Publishing.

Sloan, Brian. (2016). The Changing Concept of 'Family' and Challenges for Family Law in Ireland, en Scherpe, Jens M., European Family Law Volumén II, The Changing Concept of 'Family' and Challenges for Domestic Family Law, University of Cambridge and Fellow of Gonville and Caius College, Cambridge, United Kingdom.

Snyder, Steven H. (2013), United States of America. En Trimmings, Katarina y otro. (2013). International Surrogacy Arrangements Legal Regulation at the International Level. United Kingdom: Hart Publishing.

Supreme Court of the United States. (1944). Price v. Machasshuchetts, 321, U.S. 158. 27 de septiembre de 2018, de Georgetown University Sitio web: https://berkleycenter.georgetown.edu/cases/prince-v-massachusetts.

Supreme Court of California. (1993). Johnson v. Calvert, 5 Cal.4th 84, 19 Cal.Rptr.2d 494; 851 P.2d 776. 20 de mayo de 1993, de Stanford Law School. Sitio web: https://scocal.stanford.edu/opinion/johnson-v-calvert-31446.

Supreme Court of Appeal of California. (1998). Buzzanca v. Buzzanca, 61 Cal. App. 4th 1412. 10 de marzo de 1998, de Justia Us Law. Sitio web: https://law.justia.com/cases/california/court-of-appeal/ 4th/61/1410.html.

Szeibert, Orsolya. (2016). The Changing Concept of 'Family' and Challenges for Family Law in Hungary, en Scherpe, Jens M., European Family Law Volumén II, The Changing Concept of 'Family' and Challenges for Domestic Family Law, University of Cambridge and Fellow of Gonville and Caius College, Cambridge, United Kingdom.

Tamargo, María del Carmen. (2007). El Subregistro de Nacimiento: El análisis de las variables de género y etnia en el Ecuador. Observatorio Social de la Niñez y Adolescencia. 27 de septiembre de 2018, De Banco Interamericano de Desarrollo Sitio Web: http:// 
www.iin.oea.org/boletines/boletin6/publicaciones-recibidas-esp/ BID-El-subregistro-de-nacimientos.pdf.

Verschelden, Gerd y otro. (2013). Belgium. En Trimmings, Katarina y otro. (2013). International Surrogacy Arrangements Legal Regulation at the International Level. United Kingdom: Hart Publishing.

Vio Grossi, Eduardo. (2012). Voto disidente del juez Eduardo Vio Grossi. 27 de julio de 2018, de Corte Interamericana de Derechos Humanos caso Artavia Murillo y otros vs. costa rica sentencia de 28 de noviembre de 2012 (Excepciones Preliminares, Fondo, Reparaciones y Costas) Sitio web: http://www.corteidh.or.cr/docs/casos/articulos/seriec_257_esp.pdf

Wells-Greco, Michael. (2013). United Kingdom. En Trimmings, Katarina y otro. (2013). International Surrogacy Arrangements Legal Regulation at the International Level. United Kingdom: Hart Publishing.

Zervogianni, Eleni. (2016). The Changing Concept of 'Family' and Challenges for Family Law in Greece. En Scherpe, Jens M., European Family Law Volumén II, The Changing Concept of 'Family' and Challenges for Domestic Family Law, University of Cambridge and Fellow of Gonville and Caius College, Cambridge, United Kingdom. 